\title{
Hydrophobic, mechanical and thermal characteristics of thermoplastic cellulose diacetate bonded with cardanol from cashew nutshell
}

\author{
Masatoshi Iji, Sungil Moon and Shukichi Tanaka \\ Polymer Journal (2011) 43, 738-741; doi:10.1038/pj.2011.57; published online 22 June 2011
}

Keywords: cardanol; cellulose diacetate; heat resistance; hydrophobicity; tenacity; thermoplastic

Biomass-based plastics (bioplastics), prepared using renewable plant resources as raw materials, have been attracting increased attention for use in environmentally sensitive applications in the face of petroleum resource depletion and global warming. Currently, mass-produced bioplastics such as polylactic acid (PLA) ${ }^{1,2}$ use starch as the main resource, and starch is produced from plants that are generally edible. However, fear of future food shortages is driving an effort to use plant resources that are not edible.

We focused on two inedible plant resources with stable supply: cellulose, the main component of most plants and the largest amount of non-food plant resource produced in the ground, and cardanol, a unique-structured organic compound derived from cashew nutshell generated in large amounts as a by-product.

Cellulose is a polysaccharide consisting of D-glucose units linked together by $\beta 1-4$ glycosidic bonds into linear chains. It has an extensive hydrogen-bonded and partially crystallized structure that makes it very stiff, non-melt processible and insoluble in water and most organic solvents. Esterification is commonly used to produce thermoplastics from cellulose, mainly by using various acids such as acetic acid, propionic acid and nitric acid. ${ }^{3}$ Because of their narrow windows between the melting and degradation temperatures, large amounts of external plasticizers such as glycerin, polyethylene glycol and triethyl citrate generally must be added. ${ }^{4}$ However, adding an external plasticizer can reduce the maximum strength and heat resistance of cellulose ester composites, making them unsuitable for various types of durable products such as electronic devices.

Various ways of overcoming this problem have been investigated. They include modification of cellulose and its derivatives, such as by bonding the long-chain alkyl compounds or by grafting various polymers with cellulose and its derivatives. The bonding and grafting agents used serve as internal plasticizers and provide additional properties. Several studies investigated the use of cellulose acetates, which are soluble in several common organic solvents, as a precursor in the grafting of various linear polymers, ${ }^{5}$ including å-caprolactoneL-lactide copolymers, ${ }^{6}$ PLA $^{7,8}$ and styrene-maleic anhydride random copolymers. ${ }^{9}$ More recent studies have investigated the use of pure cellulose as a precursor by using special solvents, such as $N$, $\mathrm{N}$-dimethylacetamide/lithium chloride and ion liquids such as 1-allyl-3-methylimidazolium chloride ${ }^{10}$ to dissolve the cellulose. In these solvents, long-chain alkanoic acids (carbon number: 12-20) were bonded ${ }^{11}$ and graft copolymerization was conducted using various monomers such as lactic acid ${ }^{12}$ and methacrylate. ${ }^{13}$ However, the cellulose-based bioplastics produced in these studies did not have sufficient water resistance, strength and heat resistance for practical use in various durable products. Moreover, the bonding and grafting agents used were made of a petroleum product or starch.

Cardanol is a main organic ingredient (about $30 \mathrm{wt} \%$ ) in cashew nutshell. ${ }^{14,15}$ Cashew nut is an agricultural renewable resource, and cashew trees (Anacardium occidentale L.) are widely planted in tropical countries such as India and Vietnam. A large amount of the shell is generated as a non-edible by-product. Cardanol is a phenol derivative consisting of unsaturated hydrocarbons as a flexible and hydrophobic long side chain (carbon number: 15) and phenol as a rigid aromatic part with a reactive hydroxide group. It is superior to common phenol derivatives in terms of many practical characteristics such as water resistance, flexibility and friction when used as a major component in thermosetting plastics such as phenol resins and epoxy resins. ${ }^{16-18}$ These resins are mainly used in surface coatings, insulating materials, adhesives and friction materials.

As cardanol is a flexible and hydrophobic chain-like organic compound, we hypothesized that combining it with cellulose to produce a stiff backbone would result in a bioplastic with good thermoplasticity and high durability characteristics such as high water resistance, great tenacity (large elongation at breaking point while maintaining high maximum strength) and high heat resistance. However, there have been few studies on cellulose derivatives bonded with cardanol. Cardanol has been bonded to natural cellulose fiber (in sheet form) using a cationic catalyst ${ }^{19}$ to retard water penetration through the reaction of the unsaturated bonds in the alkyl side chain of the cardanol and the hydroxide group in the cellulose fiber. 
A cardanol derivative of toluene diisocyanate has been bonded to sisal fiber, which is composed mainly of cellulose, to reduce the hydrophilic nature of the fiber. ${ }^{20}$ However, to the best of the authors' knowledge, the hydrophobic, mechanical and thermal characteristics of thermoplastics produced by bonding cardanol with cellulose derivatives have not been reported.

In the study reported here, we investigated the hydrophobic, mechanical and thermal characteristics of a thermoplastic cellulose diacetate (CDA) bonded with cardanol. Cardanol was modified to enhance its reactivity with the CDA. We used hydrogenated cardanol, in which the unsaturated bonds in the alkyl side chain were changed to saturated ones by adding hydrogen to prevent crosslinking between the cardanol molecules during bonding with the CDA. The hydroxide group of the phenol in the cardanol was changed to acetic acid chloride group to achieve esterification with the hydroxide groups in the CDA. The preparation is described in detail in the Supplementary Information. The hypothesized structure of the cardanol-bonded CDA is illustrated in Figure 1. We found that bonding the modified cardanol (cardanoxy acetic acid chloride) with CDA resulted in a bioplastic with good thermoplasticity, high water resistance, great tenacity and high heat resistance.

The thermoplasticity of the cardanol-bonded CDA was estimated by measuring the melt flow rate $\left(200^{\circ} \mathrm{C}, 500-\mathrm{kgf} \mathrm{cm}^{-2} \mathrm{load}\right)$, which increased as the ratio of the bonded cardanol was increased (Table 1). The cardanol-bonded CDA (cardanol acetic acid: $41 \mathrm{wt} \%$, degree of subsitution*: 0.50) had sufficient thermoplasticity for molding even without the use of an external plasticizer $\left({ }^{*}\right.$ degree of substitution: ratio

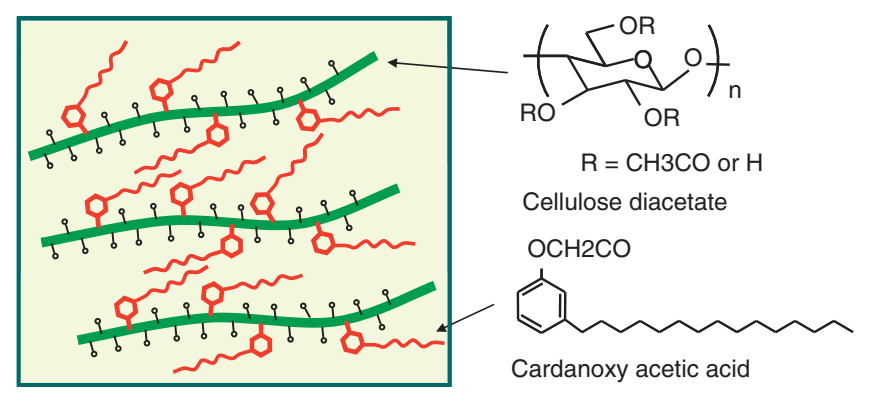

Figure 1 Hypothesized structure of cardanol-bonded cellulose diacetate. of replacing three hydroxide groups in one glucose of cellulose with cardanoxy acetic acid). This indicates that bonded cardanol functions as an effective internal plasticizer for CDA by reducing the interactions between the CDA molecules, enabling them to slip during heating. The disappearance of the melting point of the cardanol-bonded CDA, revealed by differential scanning calorimetry measurement, indicated that the structure of the cardanol-bonded CDA was amorphous. This amorphous structure is an attractive characteristic because it means that the cardanol-bonded CDA can be quickly molded into various products, as can conventional petroleum-based plastics. The reference PLA has a crystallized structure requiring annealing at a relatively high temperature (about $100^{\circ} \mathrm{C}$ ) after molding, which is an obstacle to its application to various products.

We estimated the hydrophobicity (water resistance), mechanical strength and heat resistance of the cardanol-bonded CDA and compared them with those of the reference CDA alone, composites consisting of CDA and a conventional external plasticizer: triethyl citrate, PLA and acrylonitrile-butadiene-styrene (ABS) resin, a petroleum-based plastic commonly used to fabricate components used in electronic devices.

The water resistance of the CDA was significantly improved by bonding the modified cardanol. As shown in Figure 2 and Table 1, the water absorption ratios of the cardanol-bonded CDA samples after soaking ( $24 \mathrm{~h}$ in distilled water at room temperature) decreased substantially as the proportion of the bonded cardanol was increased. They were considerably lower than those of CDA alone and of the CDA composites with the external plasticizer. The higher water resistance of the cardanol-bonded CDA was mainly due to replacement of the hydrophilic hydroxide groups in the CDA with hydrophobic cardanol groups. Moreover, the long alkyl chain and the phenyl part of the modified cardanol linked to the CDA might have protected the remaining hydroxide groups in the cardanol-bonded CDA from moisture absorption.

On the other hand, the addition of the external plasticizer to CDA insufficiently improved its water resistance (Figure 2, Table 1). Simply mixing this external plasticizer with the CDA did not effectively retard moisture penetration because of the weak interface between the CDA and the plasticizer in addition to the poor hydrophobic performance of the plasticizer. In addition to the reduced maximum strength and heat resistance, as mentioned above, the poor water resistance of

Table 1 Characteristics of cardanol -bonded cellulose diacetate and references

\begin{tabular}{|c|c|c|c|c|c|c|c|c|}
\hline \multirow[b]{2}{*}{ No } & \multirow[b]{2}{*}{ Sample content ${ }^{\mathrm{a}}$} & \multirow[b]{2}{*}{$\begin{array}{l}\text { Melt flow } \\
\text { rate } \\
\left(g^{-1} \min ^{-1}\right)\end{array}$} & \multirow[b]{2}{*}{$\begin{array}{l}\mathrm{Tg}^{\mathrm{b}} \\
\left({ }^{\circ} \mathrm{C}\right)\end{array}$} & \multirow[b]{2}{*}{$\begin{array}{c}\text { Water } \\
\text { absorption }{ }^{c} \\
\text { (wt\%) }\end{array}$} & \multirow[b]{2}{*}{$\begin{array}{c}\text { Dimension } \\
\text { change } \\
\text { ratio }^{\mathrm{d}}(\%)\end{array}$} & \multicolumn{2}{|c|}{ Bending test } & \multirow[b]{2}{*}{$\begin{array}{c}\text { Plant } \\
\text { ingredient } \\
\text { ratio (wt\%) }\end{array}$} \\
\hline & & & & & & $\begin{array}{c}\text { Strength } \\
\text { (MPa) }\end{array}$ & $\begin{array}{c}\text { Elongation } \\
\text { (\%) }\end{array}$ & \\
\hline 1 & Cellulose diacetate (CDA) & - & 227 & 17.0 & 1.90 & - & - & 64 \\
\hline 2 & CDA bonded with cardanol (31 wt\%, DS : 0.33) & 150 & 154 & 2.1 & 0.27 & 84 & $>10$ & 71 \\
\hline 3 & CDA bonded with cardanol (41 wt\%, DSe: 0.50) & 600 & 142 & 1.2 & 0.092 & 80 & $>10$ & 73 \\
\hline 4 & CDA added with plasticizer (29wt\%) & 960 & 109 & 5.9 & 0.67 & 68 & $>10$ & 41 \\
\hline 5 & CDA added with plasticizer (41 wt\%) & 1020 & 80 & 4.9 & 0.77 & 34 & $>10$ & 32 \\
\hline 6 & Polylactic acid & 1320 & 60 & 0.42 & 0.061 & 97 & 2.3 & 100 \\
\hline 7 & ABS resin & 1040 & 102 & 0.51 & 0.039 & 78 & $>10$ & 0 \\
\hline
\end{tabular}

Abbreviations: ABS, acrylonitrile-butadiene-styrene, DS, degree of substitution; Tg, glass transition temperature.

asample 1 was molded by casting (size: $0.2 \times 10 \times 60 \mathrm{~mm}$ ). Sample 2 was press-molded and other samples were injection-molded (size: $2 \times 13 \times 80 \mathrm{~mm}$ ).

${ }^{b}$ Glass transition temperature.

cMeasured by weighing before and after soaking samples for $24 \mathrm{~h}$ in distilled water at room temperature.

${ }^{\mathrm{d}}$ Measured by sizing samples before and after the water absorption test.

e Degree of substitution: ratio of replacing three hydroxide groups in one glucose of cellulose with cardanoxy acetic acid. 


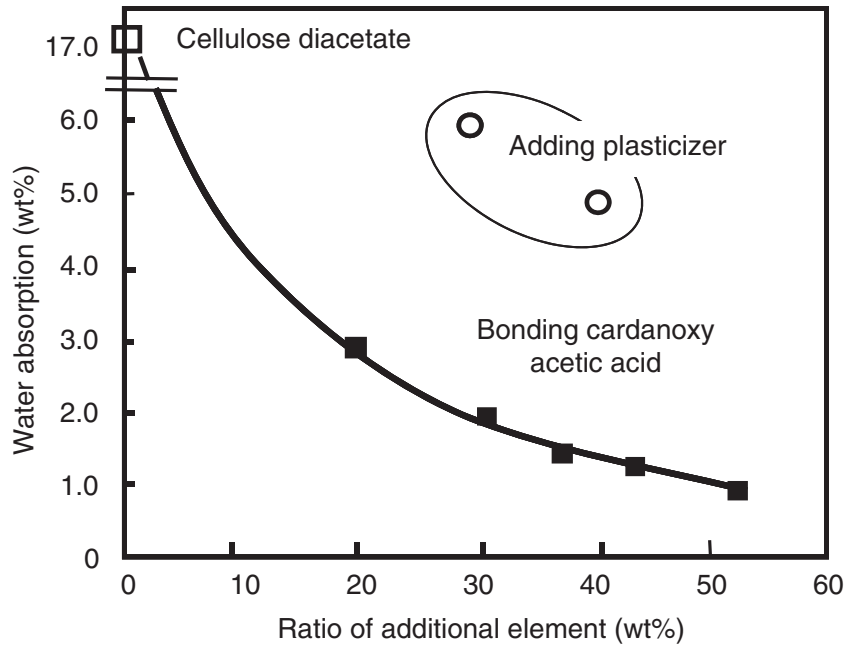

Figure 2 Water absorption of cellulose diacetate derivatives against proportion of element added to cellulose diacetate: water absorption ratio after soaking for $24 \mathrm{~h}$ in distilled water at room temperature.

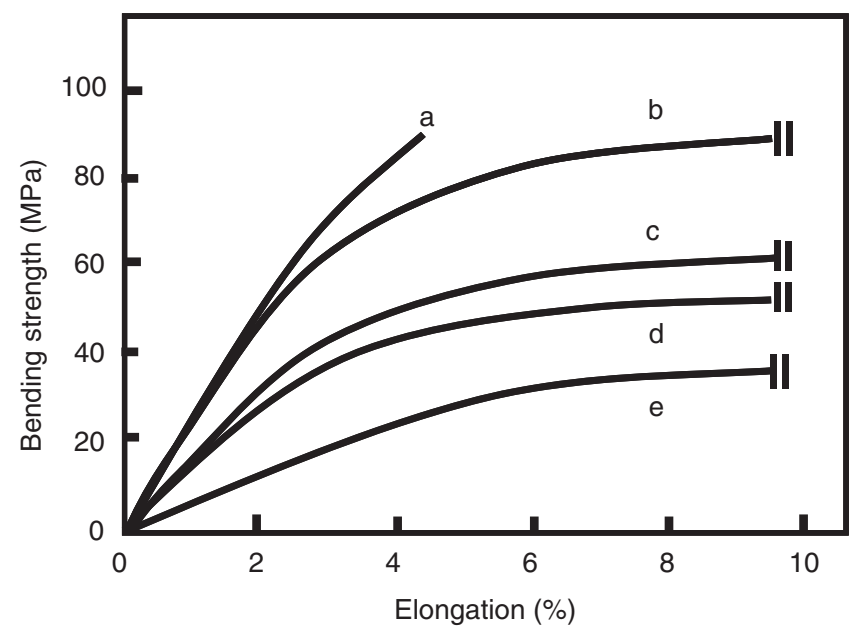

Figure 3 Bending strength of cardanol-bonded cellulose diacetate estimated as amount of bonded cardanoxy acetic acid/proportion of bonded cardanoxy acetic acid/degree of substitution: (a) 21 wt\%/0.19, (b) $31 \mathrm{wt} \% / 0.33$, (c) $38 \mathrm{wt} \% / 0.44$, (d) 43 wt $\% / 0.55$, (e) 53 wt $\% / 0.80$.

conventional cellulose ester resins, such as CDA composites with a petroleum-based plasticizer, has been a serious obstacle to their practical use in durable products. This is because the absorbed water degrades the structural stability of the products in which they are used.

As shown in Table 1, the structural stability of the cardanol-bonded CDA, estimated as the dimension change ratio after the water absorption test, was significantly better than that of the CDA composites with the external plasticizer. This was because of the water resistance of the cardanol-bonded CDA. Although the water resistance of the cardanol-bonded CDA was not comparable to those with PLA and ABS resin, the cardanol-bonded CDA (cardanoxy acetic acid: $41 \mathrm{wt} \%)$ showed good structural stability, close to those with these resins.

The mechanical characteristics of the cardanol-bonded CDA were estimated from the results of a bending test (Figure 3, Table 1). Bonding the modified cardanol with CDA greatly increased the tenacity (elongation while maintaining maximum strength) of

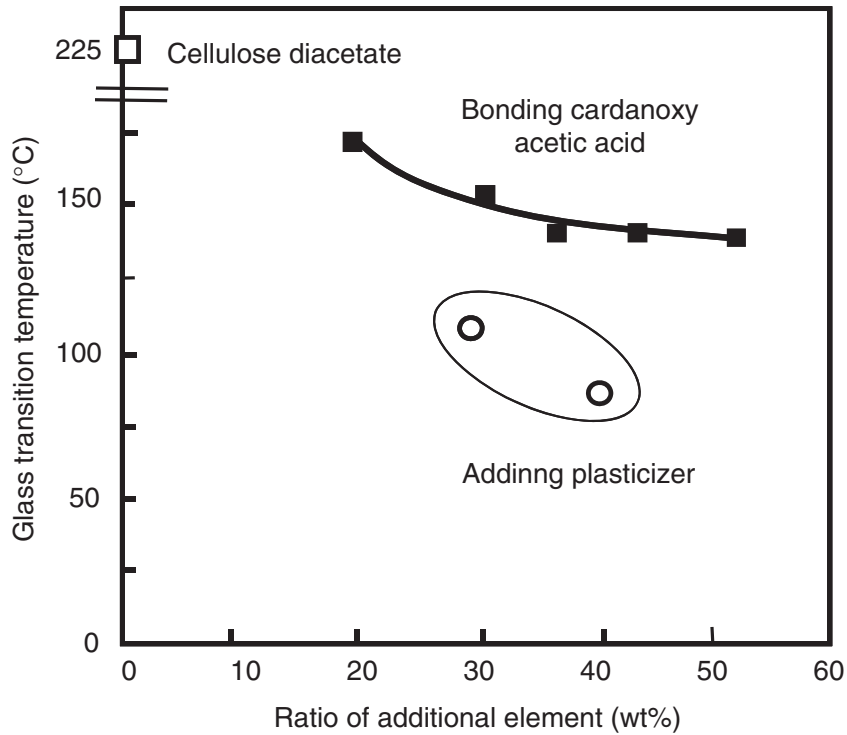

Figure 4 Glass transition temperature of cellulose diacetate derivatives against proportion of element added to cellulose diacetate.

the CDA. The cardanol-bonded CDA showed larger elongation at the breaking point as the ratio of the modified cardanol was increased. Although the maximum strength of the cardanol-bonded CDA decreased as the modified cardanol ratio was increased, it remained higher than that of the CDA composites with the external plasticizer. In particular, as shown in Table 1, the cardanol-bonded CDAs (cardanol acetic acid: 31 and $41 \mathrm{wt} \%$ ) had high strength and large elongation, comparable to those with ABS resin, and the elongation was superior to that with PLA.

The large elongation was due to the bonded cardanol functioning as an inner plasticizer, enabling the CDA molecules to slip during deformation of the cardanol-bonded CDA in the testing. The maximum strength was maintained by the chemical and physical interactions among the modified cardanol molecules linked to the CDA molecules. These interactions resulted from the high affinity and entanglement through the long alkyl side chain of the modified cardanol. In addition, the rigidity of the phenyl part of the modified cardanol restricted the motion of the cardanol-bonded CDA molecules, which helped maintain the strength. On the other hand, the considerable decrease in the maximum strength of the CDA composites with the external plasticizer was caused by low interaction between the CDA and the plasticizer, which was simply mixed with the CDA.

As shown in Table 1, the maximum strength of a cardanol-grafted CDA sample that was injection-molded (Table 1, sample 3, modified cardanol ratio of $41 \mathrm{wt} \%$ ) was higher than those of samples that were press-molded (Figure 3, cardanol acetic acid: 38 and $43 \mathrm{wt} \%$ ). This is attributed to suppression of the formation of cavities and voids in the test pieces during the injection molding.

The heat resistance of the cardanol-bonded CDA was estimated by measuring the glass transition temperature ( $\mathrm{Tg}$ ) using differential scanning calorimetry analysis. Although the Tg of the cardanolbonded CDA decreased as the proportion of the modified cardanol was increased, it remained higher than those of the CDA composites with the external plasticizer, as shown in Figure 4 and Table 1. As Tg is mainly affected by the ease of movement of polymer molecules during heating, the maintenance of the high Tg by the cardanol-bonded CDA was apparently due to high interaction among the long alkyl chains of 
the modified cardanol molecules linked to the CDA molecules, as well as the inclusion of its rigid phenyl part, which is similar to the highstrength mechanism of the cardanol-bonded CDA described above. The lower Tg of the CDA composites containing the external plasticizer resulted from the low interaction between the CDA molecules and the plasticizer molecules.

The plant constituent ratios of the cardanol-bonded CDAs (Table 1) were higher than those of the CDA composites containing the petroleum-based plasticizer added in usual amounts $(20-40 \mathrm{wt} \%)^{11}$. The remaining main petroleum ingredient of the cardanol-bonded CDA was acetic acid in the CDA.

In summary, we investigated the hydrophobic, mechanical and thermal characteristics of cardanol-bonded CDA. Cardanol, a main ingredient of cashew nutshells and a phenol derivative with a long alkyl side chain, was modified to enhance the bonding reaction. The unsaturated bonds in the chain were hydrogenated, and the hydroxide group of the phenol unit was changed to acetic acid chloride group. Bonding the modified cardanol with CDA resulted in a bioplastic with good thermoplasticity, high water resistance, great tenacity and high heat resistance. These properties were considerably better than those of conventional CDA composites consisting of CDA and a conventional external plasticizer. The heat resistance was higher than those of PLA and ABS resin, and its tenacity was better than that of PLA and comparable to that of ABS resin. The cardanol-bonded CDA is, thus, a promising bioplastic for use in durable products such as electronic devices in addition to general products.

\section{ACKNOWLEDGEMENTS}

We are grateful to Mr Hideki Honzawa, Tohoku Chemical Industries and to Mr Hiroyuki Kai, University of California, Berkeley, for their supporting experiments.

1 Li, S., Ernst, W. \& Martin, P. Present and future development in plastics from biomass. Biofuels Bioprod Bioref 4, 5-40 (2010).

2 Serizawa, S., Inoue, K. \& Iji, M. Kenaf-Fiber-reinforced poly(lactic acid) used for electronic products. J. Appl. Polym. Sci. 100, 618-624 (2006).
3 Zepnik, S., Kesselring, A., Kopitzky, R. \& Michels, C. Basics of cellulosics. Bioplastic Magazine 5, 44-47 (2010).

4 wan-Man, P. Manjusri, M., Lawrence, T. D. \& Mohanty, A. K. Green nanocomposites from cellulose acetate bioplastic and clay: effect of eco-friendly triethyl citrate plasticizer. Biomacromolecules 5, 2281-2288 (2004)

5 Roy, D., Semsarilar, M., Guthrie, J. T. \& Perrier, S. Cellulose modification by polymer grafting: review. Chem. Soc. Rev. 38, 2046-2064 (2009).

$6 \mathrm{Nie}$, L. \& Narayan, R. Grafting cellulose acetate with styrene maleic anhydride random copolymers for improving dimensional stability. J. Appl. Polym. Sci. 54, 601-617 (1994).

7 Yoshioka, M., Hasegawa, N. \& Shiraishi, N. Themoplastization of cellulose acetates by grafting of cyclic esters. Cellulose 6, 193-212 (1999)

8 Teramoto, Y. \& Nishio, Y. Cellulose diacetate-graft-poly(lactic acid)s: synthesis of wide-ranging compositions and their thermal and mechanical properties. Polymer 44, 2701-2709 (2003).

9 Teramoto, Y. \& Nishio, Y. Biodegradable cellulose diacetate-graft-poly(L-lactide)s: enzymatic hydrolysis behavior and surface morphological characterization. Biomacromolecules 5, 407-414 (2004).

10 Edgar, K. J., Pecorini, T. J. \& Glasser, W. G. Preparation, Properties, and Perspective, Cellulose Derivatives Ch.3, 38-60, ACS Symposium Series, Volume 688, (American Chemical Society, Washington, 1998).

11 Sealey, J. E., Samaranayake, G., Todd, J. G. \& Glasser, W. G. Novel cellulose derivatives. iv. Preparation and thermal analysis of waxy esters of cellulose. J. Polym. Sci.: Part B Poly. Phys. 34, 1613-1620 (1996).

12 Chenghu, T., Jinming, Z., Yuxia, L., Jian, Y., Jin, W., Jun, Z. \& Jiasong, H. Thermoplastic cellulose-graft-poly(L-lactide)copolymers homogeneously synthesized in an ionic liquid with 4-dimethylaminopyridine catalyst. Biomacromolecules 10, 2013-2018 (2009).

13 Enomoto-Rogers, Y., Kamitakahara, H., Takano, T. \& Nakatsubo, F. Cellulosic graft copolymer: poly(methacrylate) with cellulose side chain. Biomacromolecules 10 , 2110-2117 (2009).

14 Kumar, P. P., Parmashivappa, R., Vithayathil, P. J., Rao, P. V. S. \& Rao, A. S. Process for isolation of cardanol from technical cashew (Anacardium occidentale L.) nut shell liquid. J. Agri. Food Chem. 50, 4705-4708 (2002).

15 Lubi, M. C. \& Thachil, E. T. Cashew nut shell liquid (CNSL)- a versatile monomer for polymer synthesis. Designed Monom. Polym. 3, 123-153 (2000).

16 Devi, A. \& Srivastava, D. Studies on blends of cardanol-based epoxidized novolac type phenolic resin and carboxyl-terminated polybutadiene (CTPB) I. Mater. Sci. Eng. A, 458, 336-347 (2007)

17 Antony, R. \& Pillai, C. K. S. Synthesis and thermal characterization of chemically modified cardanol polymers. J. Appl. Polym. Sci. 49, 2129-2135 (1993).

18 Maffezzoli, A., Calo, E., Zurlo, S., Giuseppe, M., Tazia, A. \& Stifani, C. Cardanol based matrix biocomposites reinforced with natural fibers. Com. Sci. Tech. 64, 839-845 (2004).

19 John, G. \& Pillai, C. K. S. Grafting of bio-monomers. 1.Cationic graft copolymerisation of cardanol using borontrifluoridedietyletherate onto cellulose. Polymer Bulletin 22, 89-94 (1989).

20 Joseph, K., Thomas, S. \& Pavithran, C. Effect of chemical treatment on the tensile properties of short sisal fibre-reinforced polyethylene composites. Polymer $\mathbf{3 7}$, 5139-5149 (1996).

Supplementary Information accompanies the paper on Polymer Journal website (http://www.nature.com/pj) 